\title{
Social learning in New Caledonian crows
}

\author{
Jennifer C. Holzhaider, Gavin R. Hunt, and Russell D. Gray \\ University of Auckland, Auckland, New Zealand
}

\begin{abstract}
New Caledonian (NC) crows are the most sophisticated tool manufacturers other than humans. The diversification and geographical distribution of their three Pandanus tool designs that differ in complexity, as well as the lack of ecological correlates, suggest that cumulative technological change has taken place. To investigate the possibility that high-fidelity social transmission mediated this putative ratchet-like process, we studied the ontogeny of Pandanus tool manufacture and social organization in free-living NC crows. We found that juvenile crows took more than 1 year to reach adult proficiency in their Pandanus tool skills. Although trial-and-error learning is clearly important, juveniles have ample opportunity to learn about Pandanus tool manufacture by both observing their parents and interacting with artifactual material. The crows' social system seems likely to promote the faithful social transmission of local tool designs by both favoring the vertical transmission of tool information and minimizing horizontal transmission. We suggest that NC crows develop their Pandanus tool skills in a highly scaffolded learning environment that facilitates the cumulative technological evolution of tool designs.
\end{abstract}

Social learning may be defined as "learning that is influenced by observation of, or interaction with, another animal (typically a conspecific) or its products" (Heyes, 1994; cf. Box, 1984; Galef, 1988). It comprises a variety of mechanisms that range in sophistication from cognitively low-level local and stimulus enhancement to highlevel imitation. In the case of local enhancement, an individual is more likely to discover a new behavior simply because it is drawn to a location at which a conspecific is active. Similarly, an object might be more salient to an individual because a conspecific has been handling it, but each individual discovers the object's affordances for itself (e.g., the appropriate length and diameter of sticks to probe for honey or termites). Imitation, generally considered the most cognitively demanding form of social learning, can be defined as copying the exact form of an agent's actions (Tomasello, 1999). In contrast, emulation describes the copying of an action's outcome, rather than a motor pattern. The extent to which human and nonhuman animals rely on imitation and emulation to acquire skills from conspecifics is controversial.

Many experiments have shown that imitation is crucial for children who are learning tool skills (Call, Carpenter, \& Tomasello, 2005; Horner \& Whiten, 2005; Want \& Harris, 2001, 2002), but nonhuman primates have been thought mainly to emulate. For example, several studies have found no evidence that chimpanzees (Pan troglodytes) or orangutans (Pongo pygmaeus) can copy the actions of conspecifics in tasks that require tool use to retrieve food (Call \& Tomasello, 1994; Myowa-Yamakoshi \& Matsuzawa, 1999; Nagell, Olguin, \& Tomasello, 1993; Tomasello, Davis-Dasilva, Camak, \& Bard, 1987). However, Tomasello, Savage-Rumbaugh, and Kruger (1993) found that the imitation ability of enculturated chimpanzees was similar to that of 2.5 -year-old children. Also, a review of 31 experiments with apes reported numerous cases of both imitative behavior and emulation (Whiten, Horner, Litchfield, \& Marshall-Pescini, 2004). In general, much of the socially learned behavior of nonhuman primates appears to consist of a combination of different mechanisms such as imitation, emulation, and stimulus enhancement, augmented by individual trial-and-error learning (Fragaszy \& Visalberghi, 1996; Tomasello, 1996; Whiten, McGuigan, Marshall-Pescini, \& Hopper, 2009).

Culture has been defined as socially learned behavior patterns that are customary in some communities but absent in others, without ecological explanations for the variation (Laland \& Hoppitt, 2003; Whiten et al., 1999). Under this definition, culture has been reported in a wide range of animals and contexts. Examples include dialects in songbirds (Catchpole \& Slater, 1995; Marler \& Tamura, 1964; Mundinger, 1980) and humpback whales (Megaptera novaeangliae) (Noad, Cato, Bryden, Jenner, \& Jenner, 2000; Rendell \& Whitehead, 2001), and diverse behaviors in nonhuman primates (chimpanzees, McGrew, 1992; Whiten et al., 1999; orangutans, Pongo pygmaeus, van Schaik et al., 2003; capuchin monkeys [Cebus species], Ottoni \& Izar, 2008; Perry et al., 2003).

Which social learning mechanisms are crucial for the development and transmission of culture? In some cases, the spread of cultural traditions is probably best explained by the cognitively simpler mechanisms of local and stimulus enhancement (e.g., potato and grain washing in Japanese macaques; Avital \& Jablonka, 2000; Kawai, 1965). However, more complex traditions, such as nut cracking and tool manufacture, might require a higher degree of

J. C. Holzhaider, jenny.holzhaider@gmail.com 
fidelity of transmission between individuals (Tomasello, Kruger, \& Ratner, 1993). Faithful transmission would be particularly important for incremental improvements in traditions and artifacts over time (Boserup, 1981; Boyd \& Richerson, 1996; Tomasello, 2005), because only faithful transmission can create a ratchet effect that ensures that existing techniques or artifacts are maintained and reliably reproduced until new improvements appear (Tomasello, Kruger, \& Ratner, 1993).

Some authors have claimed that only very specific types of social learning - namely, imitative, instructed, and collaborative learning — can lead to cumulative cultural transmission (Boyd \& Richerson, 1996; Tomasello, 1996). Others have challenged this view (Claidière \& Sperber, 2010; Heyes, 1993; Laland \& Hoppitt, 2003). Claidière and Sperber claimed that imitation might well be important for the propagation of animal culture, but it is not faithful enough to explain its stability. Heyes (1993) argued that fidelity of transmission relies on insulating socially transmitted information from individual modification, rather than from a particular learning process. Information stored in artifactual material might provide one of these insulating processes ("external memory," Donald, 1991). For example, information about the design of currently used tools could be obtained from an inspection of existing tools, as well as from directly observing tool manufacturing techniques. Adult chimpanzees, for example, frequently allow juveniles to use and interact with objects that they had just used as tools (Biro, Sousa, \& Matsuzawa, 2006; Matsuzawa et al., 2001). Laboratory experiments have confirmed that the use of tools that were previously used by an experienced individual can support the acquisition of tool skills in naive individuals (Hirata \& Celli, 2003; Hirata \& Morimura, 2000).

Animals commonly modify their environment in a variety of ways - for example, by leaving tools or facilitating access to food sources, thereby shaping the environment in which their offspring mature. This process was termed niche construction by Laland et al. (Laland, Odling-Smee, \& Feldman, 2000; Odling-Smee, Laland, \& Feldman, 2003; Sterelny, 2006) and might lead to the faithful transmission of behavior even in the absence of high-level social-learning mechanisms, such as imitation (Reisman, 2007).

However, despite the many examples of sophisticated behavior such as tool use and the associated potential for cultural transmission, evidence of cumulative change in nonhuman animals is exceedingly rare (Boyd \& Richerson, 1996; Whiten, 2005). Song dialects in birds provide a well-documented example (Baker \& Cunningham, 1985; Mundinger, 1980).

Chimpanzees exhibit many aspects of tool use that have been claimed to be unique to humans, such as the possession of "tool kits" with different tools for different functions (Boesch, Head, \& Robbins, 2009), or the use of tools for underground food extraction (HernandezAguilar, Moore, \& Pickering, 2007; Sanz, Morgan, \& Gulick, 2004). Sanz, Call, and Morgan (2009) recently documented that chimpanzee populations in the Congo Basin deliberately modify the tips of their termite-fishing probes into "brushes" to improve their efficiency before they are first used. The authors suggested that the brush probes are an improvement to an existing, simpler design. However, because the brush modification is a sequential addition to an existing manufacturing process, it is difficult to know whether brush manufacturing is transmitted socially or is due to individual trial-and-error learning.

Research on the cognition associated with folk physics and social learning in nonhuman animals has traditionally focused on primates. More recently, however, another animal group has received considerable attention in these areas of cognitive research: corvids. Corvids have demonstrated cognitive abilities that rival those of the great apes (Bird \& Emery, 2009, 2010; Bugnyar, 2008; Emery, 2004; Emery \& Clayton, 2009; Seed, Emery, \& Clayton, 2009; Taylor, Hunt, Holzhaider, \& Gray, 2007; Taylor, Hunt, Medina, \& Gray, 2009; Taylor, Roberts, Hunt, \& Gray, 2009; Tebbich, Seed, Emery, \& Clayton, 2007). Like the brains of primates, corvid brains are significantly larger than would be predicted from their body size (Jerison, 1973). Importantly, the relative size of the corvid forebrain, especially the nidopallium and mesopallium, which are thought to be functionally analogous to the mammalian prefrontal cortex, is larger than that of most other birds (Mehlhorn, Hunt, Gray, Rehkämper, \& Güntürkün, 2010; Rehkämper, Frahm, \& Zilles, 1991; Reiner et al., 2004).

Even the lifestyle of many corvid species appears to be similar to that of nonhuman primates. For example, colonial species such as rooks (Corvus frugilegus) or pinyon jays (Gymnorhinus cyanocephalus) live in complex, variable social groups that are reminiscent of the fissionfusion societies of chimpanzees (Clayton \& Emery, 2007). Like many primate species, corvids tend to be omnivorous, generalist foragers (Emery, 2006). It has been suggested, therefore, that similar socioecological pressures might have led to a convergent evolution of intelligence in corvids and apes (Emery \& Clayton, 2004; Seed et al., 2009).

New Caledonian crows (Corvus moneduloides, $\mathrm{NC}$ crows hereafter) stand out in the corvid family because of their exceptional ability to use and manufacture tools in both the wild (Hunt, 1996, 2000a; Hunt \& Gray, 2003, 2004a, 2004b, 2007) and the laboratory (Chappell \& Kacelnik, 2002, 2004; Weir, Chappell, \& Kacelnik, 2002; Weir \& Kacelnik, 2006), and for their considerable problem-solving skills (Taylor et al., 2007; Taylor, Hunt, et al., 2009; Taylor et al., 2010; Taylor, Roberts, et al., 2009; Wimpenny, Weir, Clayton, Rutz, \& Kacelnik, 2009). NC crows also appear to have relatively large brains, even among highly encephalized corvids (Cnotka, Güntürkün, Rehkämper, Gray, \& Hunt, 2008; Mehlhorn et al., 2010). In the wild, NC crows are one of the few species that habitually manufacture tools, and the diversity of tools that they manufacture is matched only by chimpanzees (Whiten et al., 1999) and orangutans (van Schaik et al., 2003). Indeed, we believe that the strongest evidence for human-like cumulative technological evolution in a nonhuman is provided by NC crows' manufacture of tools from the leaves of Pandanus species trees (Hunt $\&$ Gray, 2003). 


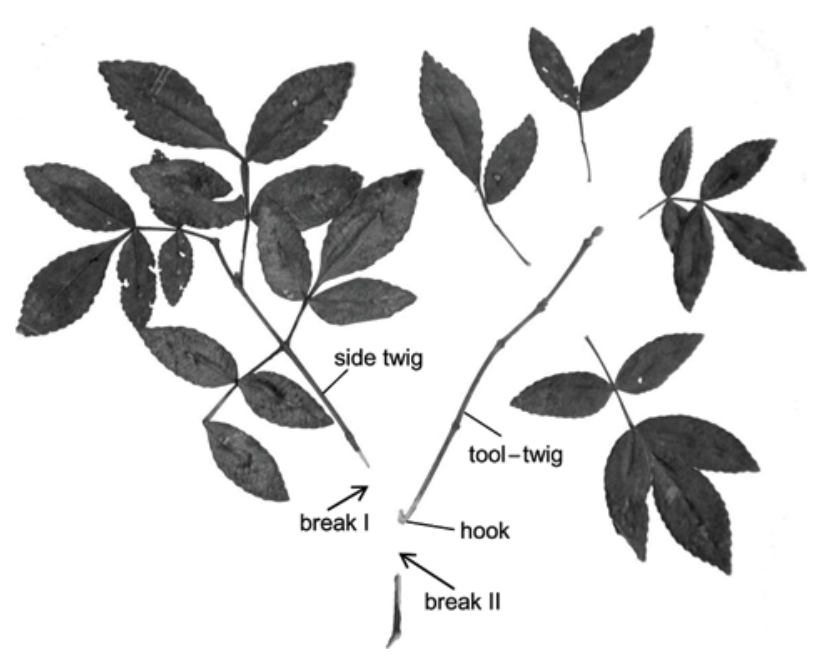

Figure 1. Manufacture of a hooked-twig tool. A crow breaks off and discards the side twig (break I) before snapping the tool-twig off the stem just below the junction (break II). It then usually removes the leaves on the tool-twig and sculpts the hook. From "The Crafting of Hook Tools by Wild New Caledonian Crows," by G. R. Hunt and R. D. Gray, 2004, Proceedings of the Royal Society B, 271, p. 89. Copyright 2004 by the Royal Society. Adapted with permission.

NC crows manufacture two types of tools (Hunt, 1996): stick tools (Hunt \& Gray, 2002) and tools made from the barbed edges of Pandanus species leaves (Hunt \& Gray, 2003, 2004b). Stick tools can be made by simple modifications to twigs and similar stick-like materials, or by a much more complicated process to create hooked tools from fresh twigs (Hunt, 1996; Hunt \& Gray, 2004a). The latter process first involves discarding one side of a forked twig and then breaking off the remaining side just below the base of the fork. The crow then usually removes the leaves from the twig and sculpts a hook from the short stump on the wide end of the tool (Figure 1).

Pandanus tools are manufactured to three different designs: uniformly wide, uniformly narrow, and stepped or tapered (Hunt \& Gray, 2003) (Figure 2). The crows use the naturally occurring barbs along one edge of these tools to hook prey such as slugs and insects out of Pandanus species and other trees. Stepped tools have the most complex shape and combine the advantages of the other two designs. Stepped tools, like narrow tools, are thin and flexible at the probing end, but like wide tools are sturdy and easy to grip at the proximal end that is held in the bill. Importantly, the design of a particular Pandanus tool is determined before or at the start of manufacture, and a tool is functional only after the final cut that separates it from a leaf. Therefore, unlike tools made by other species, such as chimpanzees' brush tools, Pandanus tools cannot be made and used in a series of incremental functional steps, leading Hunt (2000a) to suggest that the shape of stepped tools is determined by a rule system before manufacture begins. After removal, an exact negative template, the counterpart, remains on the leaf edge, making it possible to reconstruct the shapes of tools made at a site over several years (Hunt, 2000a). By documenting the shapes of over 5,000 counterparts at 21 sites across mainland Grande Terre and the island of Maré, Hunt and Gray (2003) showed that each tool design is characterized by a high degree of local standardization. The specific design made at a site (e.g., a two-stepped tool) can remain the same for decades (G. R. Hunt, unpublished data), suggesting high-fidelity transmission. Furthermore, Hunt and Gray found different geographical distributions of the three-tool designs without any obvious ecological correlates. The geographical distribution patterns and absence of the recapitulation of simpler designs when making the more complex, stepped design led Hunt and Gray to suggest that diversification of Pandanus tools arose through a process of cumulative technological evolution, probably mediated by social learning.

Is there any evidence that social learning is involved in the acquisition of tool skills in NC crows? A first attempt to unravel the mechanisms involved in the ontogeny of tool use in juvenile crows was undertaken at the University of Oxford. Kenward, Rutz, Weir, and Kacelnik (2006) hand raised four $\mathrm{NC}$ crows in artificial nests and provided them with sticks and food that could be extracted only by using the sticks as tools (Kenward et al., 2006). Food retrieval was preceded by precursor actions that resembled components of proficient tool use, and all four juveniles retrieved food at approximately 70 days of age. Two of the four juvenile crows were allowed to watch tool use by their human foster parents, resulting in increased twig carrying and insertion rates. However, the tutoring did not influence the onset or proficiency of food extraction, indicating that social input might not be necessary to acquire proficiency in basic stick tool use. Development of basic tool use in the absence of social input is also seen in other bird species that habitually use tools in the wild. Woodpecker finches (Cactospiza pallida) have shown prefunctional development of tool behavior and acquired proficient stick tool use, regardless of whether they were exposed to a tool-using model (Tebbich, Taborsky, Fessl, \& Blomqvist, 2001). Similarly, naive Egyptian vultures (Neophron percnopterus) developed the technique of throwing stones to break eggs without social input (Thouless, Fanshawe, \& Bertram, 1989). However, in the Kenward et al. (2006) study, the tutored crows also had a preference to handle objects that had been manipulated by the experimenters, indicating that stimulus enhance-

\section{A}

B

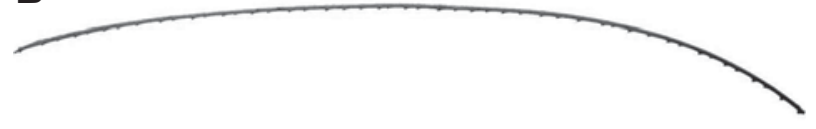

C

Figure 2. The three different Pandanus tool designs described on Grande Terre. (A) Wide tool. (B) Narrow tool. (C) Stepped tool. 
ment might play a role in the acquisition of certain aspects of tool manufacture and use.

Several weeks after developing stick tool use, the four crows were each presented with artificially mounted Pandanus leaves. Each crow ripped at the leaves and removed strips of material from them. One 3-month-old crow manufactured a leaf strip and used it as a probe on its first day of exposure to the leaf (Kenward, Weir, Rutz, \& Kacelnik, 2005). Kenward et al. (2005) and Kenward et al. (2006) therefore concluded that basic tool use and basic Pandanus tool manufacture can develop from a disposition to manipulate tool-like material to try and obtain out-ofreach food, without social input. They cautioned, however, that social learning might play a role in the acquisition of "specific techniques and tool shapes."

Observations of a hand-raised male NC crow at Parc Zoo-Forestier, Nouméa, confirmed that basic stick tool skills can develop without social learning (Hunt, Lambert, \& Gray, 2007). This crow also tore off pieces of provided Pandanus species leaves, but did not use them as tools. Similarly, when four captive adult crows that probably lacked experience with Pandanus species leaves were given the opportunity to use and manufacture Pandanus tools, only two of them probed with the provided tools, and none manufactured tools. Hunt et al. proposed that a disposition for basic stick tool skills evolved early in the history of the NC crow's tool behavior. With this disposition in place, crows then enhanced their stick tool skills and developed Pandanus tool skills through individual and social learning. Interestingly, although the five young, naive crows at Nouméa and the University of Oxford laboratory ripped strips of material off Pandanus species leaves that could be used to extract meat, none of these leaf tools resembled any of the three Pandanus tool designs described in the wild. The lack of shape consistency with the tools made in the wild might have been due to a lack of practice, or possibly to impoverished living conditions. Adult crows that are held captive in our own outdoor aviary on Maré also sometimes indiscriminately tear at the leaves on Pandanus species trees that are provided in their cages without using most of the removed material as tools.

Another surprising aspect of Kenward et al.'s (2005) and Kenward et al.'s (2006) studies was the short period of time in which the naive hand-raised juveniles learned to use and manufacture tools. All four juveniles were less than 3 months old when they successfully extracted meat with sticks, and by 3 months of age, one subject had manufactured Pandanus tools and used them to extract meat. This rapid skill acquisition clearly contrasts with the ontogeny of tool use in young primates, both human and nonhuman. For example, children require many months to successfully use a spoon to eat (Connolly \& Dalgleish, 1989), and even longer to accomplish more sophisticated tasks. Young chimpanzees at Bossou in Guinea, as well as tufted capuchins (Cebus apella) in Brazil, take well over 2 years to learn to crack nuts (de Resende, Ottoni, \& Fragaszy, 2008; Inoue-Nakamura \& Matsuzawa, 1997). Chimpanzees do not reach adult proficiency at nut cracking until they are 9 to 10 years old (Matsuzawa, 1994). Similarly, by 6 years of age chimpanzees are still less ef- ficient at ant dipping than adults (Humle, 2006; Nishida \& Hiraiwa, 1982).

Although research on hand-raised animals in the laboratory enables observations under controlled conditions, such research cannot model all of the processes that might lead to the development of complex behaviors in the wild. Only a field study can fully investigate the interactions between parents and offspring that might facilitate social learning (see, e.g., Jaeggi et al., 2010).

Determining the extent of any social learning associated with tool manufacture and use in $\mathrm{NC}$ crows requires insight into their social organization and the extent of their parental care, as well as into the ontogeny of their tool skills. Social organization is of interest because it can reveal possible pathways of social transmission.

Early observations of $\mathrm{NC}$ crows have suggested that they live most often in small family groups (Hunt, 2000b; Kenward, Rutz, Weir, Chappell, \& Kacelnik, 2004). Hunt (2000b) observed a nutritionally independent juvenile moving around with adults and suggested that the 30 or more crows he observed in a tree at the Sarraméa site on Grande Terre were a temporary aggregation of small groups. Kenward et al. (2004) saw NC crows flying above the canopy on Grande Terre in groups that were typically composed of three to four individuals, and they captured crows in small mixed-sex groups, which is consistent with the hypothesis that $\mathrm{NC}$ crows live most frequently in small family groups.

In the following account, we will describe the results of an extended field study conducted between 2003 and 2008 on the island of Maré, where $\mathrm{NC}$ crows habitually manufacture only uniformly wide Pandanus tools. The study focused on both the social organization of NC crows and the ontogeny of Pandanus tool skills in juvenile crows (Holzhaider, Hunt, \& Gray, 2010; Holzhaider et al., in press). We found that the social organization of $\mathrm{NC}$ crows is suitable for enabling the cumulative technological evolution suggested by Hunt and Gray (2003), and that different forms of learning - both social and individual - may be involved in the development of wide-Pandanus-tool manufacture in juvenile crows.

\section{METHOD}

The study site was approximately $1.5 \mathrm{~km}^{2}$ of primary and secondary rain forest that was $5-\mathrm{km}$ inland from Wabao village, where we had individually color banded over 100 crows between 2003 and 2006. Forest areas are interspersed with garden patches in which local villagers grow fruit and vegetables. These gardens, in which there are still many dead trees, are usually used for 2 consecutive years before they become overgrown. Crows forage in both forest and garden patches.

Our main method of studying free-living $\mathrm{NC}$ crows at the site was to observe them at feeding tables that were set up either in the forest or in garden patches (Figure 3). The tables, made from wood found in the vicinity, were situated about $1 \mathrm{~m}$ above the ground and were provided with fresh papaya (Carica papaya) to attract crows. Observations were made from hides that were set up around 5-7 m from the tables. Whenever possible, we videotaped observations with either a handheld video camera or a camera that was operated remotely by a motion detector. To observe Pandanus tool manufacture, we positioned a fresh Pandanus species tree at the table. To provide naturalistic tool manufacture opportunities, the tree was 


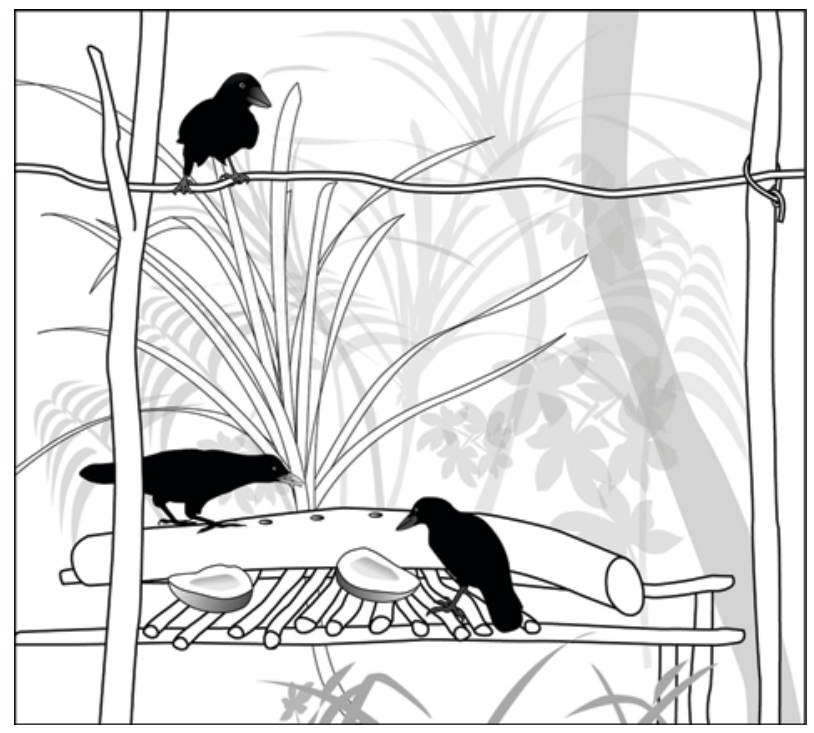

Figure 3. Example of a feeding table at the Maré study site. We used fresh papaya on the tables to attract crows. A Pandanus tree is attached behind the table to provide the opportunity for naturalistic tool manufacture. The log on the table is baited with meat placed in drilled holes to allow tool use under standardized conditions.

generally left in its original state except for the trimming of leaves that overhung the table. To create standardized opportunities for tool use, we drilled holes (ca. $2.5 \mathrm{~cm}$ in diameter and ca. $7 \mathrm{~cm}$ deep) into dead logs that were placed on the tables. These holes were baited with pieces of meat that crows could extract only using tools.

It has been suggested that our approach of observing crows from hides at artificial feeding sites prohibits the collection of behavioral data in a naturalistic setting (Bluff, Troscianko, Weir, Kacelnik, \& Rutz, 2010; Rutz, Bluff, Weir, \& Kacelnik, 2007). However, field experiments manipulating the environment of study individuals have a long-standing tradition in animal research (Reader \& Biro, 2010). For example, valuable insights into the ontogeny of chimpanzee nutcracking behavior have been obtained using a methodology similar to ours (Inoue-Nakamura \& Matsuzawa, 1997; Matsuzawa, 1994). Although our methods were not suitable to study natural sites of Pandanus and stick tool use, we believe they were appropriate for studying naturalistic Pandanus tool manufacture, since conditions in Pandanus trees in the forest away from feeding sites are not different from those at our tables. Furthermore, by standardizing the characteristics of probe sites, we could compare the proficiency of tool use between individuals. Our observations did not disturb the crows' daily routines or interfere with their family relationships. We therefore believe that our observations are generally indicative of NC crows' behavior in the wild. A recent study investigating $\mathrm{NC}$ crows' stick tool use at natural foraging sites on Grande Terre (Bluff et al., 2010) confirmed the ecological validity of our approach. Bluff et al. reported findings similar to those we have obtained at our feeding tables (Holzhaider et al., 2010) regarding juveniles' opportunity to use discarded tools and to observe parental tool use. There are, however, two possible limitations of our methodology. First, because the tables provided a continuous, valuable food source, they were probably more salient to crows than natural feeding sites, such as Pandanus species trees in the forest or papaya trees in gardens. Consequently, crows might be attracted to the tables, bringing them into closer contact with conspecifics than would be the case at natural feeding sites. Second, our observations on Maré suggest that the manufacture and the use of a Pandanus tool usually occur in close proximity to one another in the same tree, whereas we separated the location of Pandanus tool manufacture (in the tree) from the location of Pandanus tool use (on the table). This separation probably caused juveniles to remain on the table to wait for food extraction while their parents made tools in the nearby tree. This spatial separation of tool manufacture and use may have reduced the frequency with which juveniles watched parents manufacture tools.

\section{RESULTS AND DISCUSSION}

\section{Development of Wide Pandanus Tool Manufacture}

To describe the ontogeny of wide Pandanus tool manufacture and use, we documented all tool-related behavior of six juvenile crows between the ages of 2 and 18 months that regularly visited our feeding tables. We defined five behavioral categories to describe tool-manufacture techniques, ranging from unsuccessful, random-like ripping at leaves to adult-like tool manufacture, and four categories to describe different stages of tool-use proficiency. We also recorded all tool use and manufacture events by accompanying parents, and whether or not juveniles appeared to watch the activities of their parents. Parentjuvenile relationships were identified by parental feeding, intensive juvenile begging toward an adult, and protracted following of an adult by a juvenile.

In contrast with the results of Kenward et al. (2005) and Kenward et al. (2006), we found that the development of proficient Pandanus tool manufacture and use in the wild is a very extended process that is comparable to the ontogeny of tool skills in both human and nonhuman primates. Our findings also suggest that social learning plays an important role in that development.

Before acquiring adult-like technical proficiency at 10 to 12 months of age, juveniles went through four different stages of nonproficient Pandanus tool manufacture (Figures 4 and 5): In Stage I, the first attempts to manufacture Pandanus tools consisted of uncoordinated ripping of Pandanus species leaves that often failed to produce a tool. If juveniles successfully removed a tool, it usually did not resemble the classic shape of an adult-made wide tool, or it lacked barbs because it was removed at unsuitable locations for manufacture. In Stage II, the production of adult-like wide tools with a well-coordinated sequence of cutting and ripping actions developed gradually. Juveniles' use of adult-like cutting and ripping actions still did not always result in the removal of a functional tool from the leaf because they made errors in the position of a cut or a rip. Adults generally position the second cut/rip action distal to the first one, and both cuts have the same depth. They can therefore remove the tool easily from the leaf and hold it in a functional orientation (i.e., with the leaf-edge barbs facing away from the working end). In contrast, juveniles sometimes placed the second cut/rip proximal to the first one. This resulted in the tools being held with the barbs facing toward the working end, which rendered them nonfunctional (Figure 5, Technique 3). Additionally, cut/rip actions may have been of uneven depth and the tool could not be removed from the leaf (Figure 5, Technique 2). In Stage III, juveniles reached adult-like technical skill in wide-tool manufacture, carrying out the 


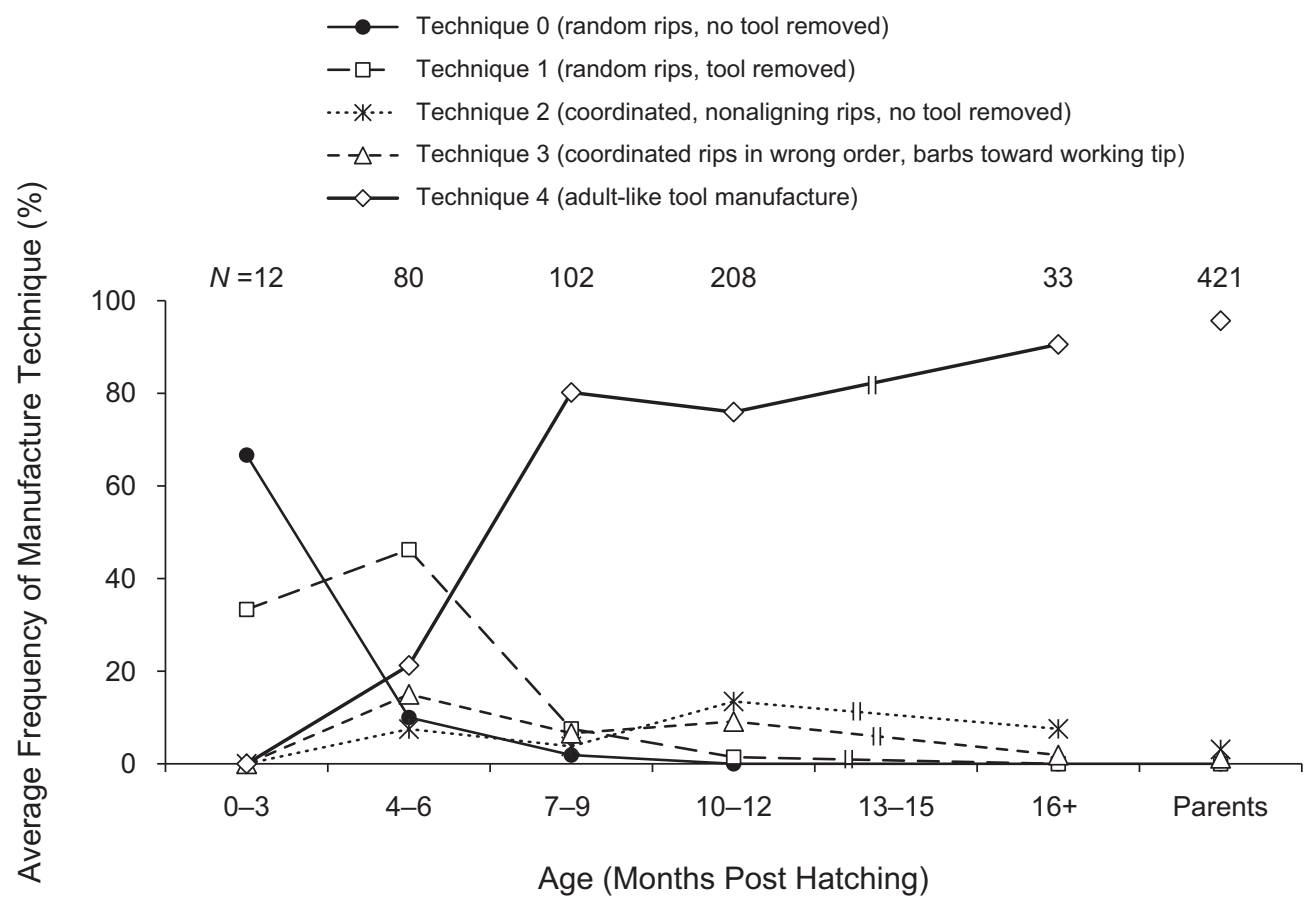

Figure 4. Development of wide Pandanus tool manufacture techniques. $N=$ the total number of tools manufactured by the members of each age class.

correct sequence of manufacture steps. Complete adultlike proficiency, however, was reached only in Stage IV, in the second year of life, when juveniles' speed of manufacture matched that of adults. For video clips of the different stages of tool manufacture, see Video 2 in Holzhaider et al. (2010).

Proficient tool-using techniques develop faster than tool-making techniques, taking approximately 7 months, because juveniles have ready access to tools that are discarded by adults. However, like Pandanus tool manufacture, proficient tool use is also preceded by a period of faulty tool use. Incorrect Pandanus tool use includes the faulty insertion of tools into holes or the use of too much force when probing so that tools are nonfunctional because they bend in the holes. Similar to what occurs in Pandanus tool manufacture, juveniles do not reach adult meat extraction speeds until at least 12 months of age.

\section{Social Learning in NC Crows}

One important mechanism by which juvenile crows learn to manufacture and use Pandanus tools appears to be individual trial-and-error learning. All of the juvenile crows that we observed spent considerable amounts of time ripping at Pandanus leaves without producing a functional tool and probing holes with unsuitable tools without extracting meat. Juveniles persisted with these behaviors often when alone on the tables. However, their learning took place in an environment that was strongly scaffolded by their parents in several ways. The first 6 months posthatching appear to be especially important for the acquisition of tool skills, with the following behaviors observed predominantly during this period:
1. Juveniles followed their parents almost constantly, and up to $40 \%$ of their time at feeding tables was in the company of at least one parent. Parents therefore likely helped to initiate tool-related behaviors via local enhancement, leading their offspring to Pandanus trees to forage.

2. Young crows were fed a considerable amount of the food that their parents had extracted, and scrounging from parents was frequently tolerated. Because the young crows were generally not rewarded by their own probing attempts until they were 6 months of age, parental feeding probably kept them motivated to use and manufacture tools. Moreover, the opportunity to scrounge from conspecifics can facilitate social learning in birds and primates (Caldwell \& Whiten, 2003; Midford, Hailman, \& Woolfenden, 2000; but see Giraldeau \& Lefebvre, 1987).

3. The first tools that juveniles used were those dropped or discarded by their parents or other experienced crows. Juveniles up to 6 months of age commonly took advantage of these ready-made tools even after they started to make their own tools (Figure 6). Given the close proximity of juveniles to their parents during their first 6 months of life, tools that they picked up were much more likely to be parental tools than those made by other crows. Like scrounging of food, the use of tools that were formerly used or manufactured by experienced conspecifics is likely to assist the development of proficient tool use in inexperienced individuals (Hirata \& Celli, 2003; Hirata \& Morimura, 2000).

By providing a juvenile's early tools, NC crow parents might also influence the emergence of juveniles' tool preferences via stimulus enhancement. Most adult crows have a strong, if not exclusive, preference to manufacture and 


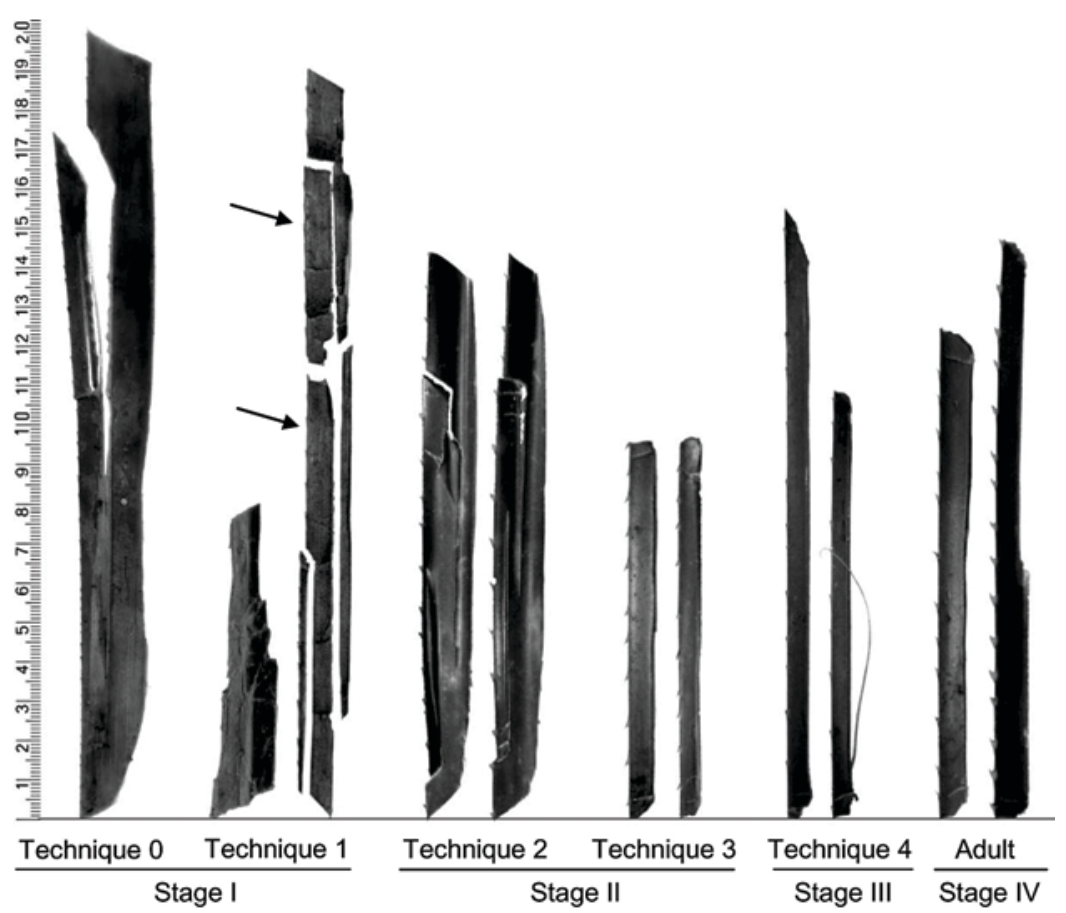

Figure 5. Four distinct stages in the development of juvenile crows' wide Pandanus tool manufacture to adult tools. In Stage I (Techniques 0 and 1), juveniles rip at leaves in an uncoordinated fashion that does not normally result in a functional tool. No tool is produced in Technique 0 . The removed leaf section at left for Technique 1 was used as a tool. The leaf section at right for Technique 1 shows multiple uncoordinated ripping; the arrows indicate the two-leaf pieces that were used as tools. In Stage II, juveniles use coordinated cutting and ripping sequences but their actions usually either do not produce a tool (Technique 2) or produce tools that are removed from the leaf in the wrong orientation (i.e., with the leaf-edge barbs pointing toward the working tip; Technique 3). In Stage III (Technique 4), juveniles produce adult-like tools but are still slower at manufacture than adults. Adult-like tool manufacture is reached in Stage IV. Because Techniques 0 and 2 do not result in a tool being removed from the leaf, we show the section of the leaf where tool manufacture had been attempted. The scale indicates centimeters.

use either stick or Pandanus tools (Hunt \& Gray, 2007). In our present study, all of the juveniles that developed a preference for Pandanus tools (4 out of 5 juveniles-i.e., $80 \%)$ had at least one parent with the same preference. Moreover, two juveniles of a pair in which both partners preferred to use stick tools also developed a preference for stick tools (Holzhaider, Hunt, \& Gray, unpublished data).

4. Counterparts created on Pandanus species leaves from tool manufacture appear to facilitate the early development of juvenile tool manufacture by providing easily accessible "starting points" for manufacture, similar to the way that juvenile black rats (Rattus rattus) can learn to remove pine cone seeds (Terkel, 1996). Until 6 months of age, juveniles often started tool manufacture at counterparts or other damaged sections of leaf edge (Figure 7). Therefore, counterparts might help juveniles to learn the appropriate location along the leaf edge at which to make a tool, and the correct depth of a rip.

5. Juveniles have ample opportunity to observe close up both tool manufacture and tool use. Parents are extremely tolerant toward their offspring, allowing body contact and even the touching of their tools by juveniles' bills. Our results show that juveniles appeared to watch tool use (i.e., probing and meat extraction) much more than they watched tool manufacture. However, as we cautioned earlier, this difference might be an artifact of the artificial spatial separation of the locations of tool manufacture and subsequent tool use at feeding tables. In Pandanus trees away from feeding tables, the manufacture and use of a wide Pandanus tool generally occurs in close proximity, in the same tree. Therefore, a juvenile watching a parent extracting prey in a Pandanus tree probably also had the opportunity to watch tool manufacture.

A detailed analysis of tool manufacture in two families revealed that crows on Maré manufacture Pandanus tools using slightly different manufacture variants (see Figure 8; for video clips of the variants, see Video 3 in Holzhaider et al., 2010). Although juveniles did not directly adopt their respective parents' preferred variant, the distribution of variants was more similar within the two families than between them (Figure 9). This is consistent with the juveniles' copying one of the variants that they saw their parents use. However, the differences between the three variants are subtle and our sample size of two 


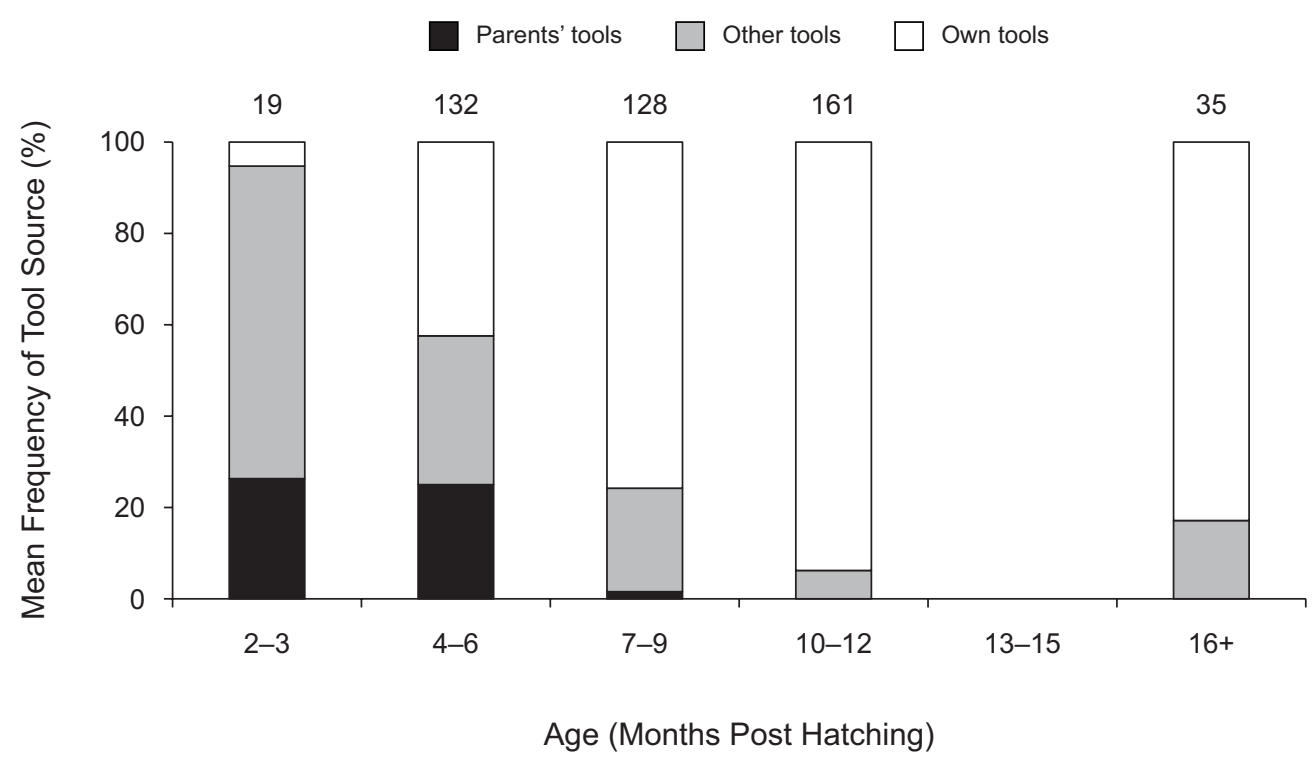

Figure 6. Origin of Pandanus tools used at tables. Numbers on top of bars give the total number of tools per age class. Note that "other tools" might also include tools manufactured by parents at earlier visits.

families was very small. Therefore, we cannot exclude the possibility that the correspondence of variants within the two families was due to chance. With a larger sample size of families, a possible method to test for nonrandomness in the frequency of variants that crows use was discussed by Kendal and colleagues (Kendal et al., 2010; Kendal, Kendal, Hoppitt, \& Laland, 2009).

An alternative mechanism mediating the transmission of tool-design information might be through "external memory" (Donald, 1991) via artifactual material, without the need for directly observing manufacture. By using parental tools, juvenile crows might form a mental template of the locally produced tool design and use this as a basis for their own tool manufacture. In this way, the wide, narrow, and stepped Pandanus tool designs could be faithfully transmitted between generations even in the absence of imitation. Template matching is a well-described process in songbirds (Doupe \& Konishi, 1991; Konishi, 1985; Nottebohm, 1984). During a sensitive period, young birds hear and memorize a tutor song. By practicing themselves, they then gradually match their own song to the memorized template. This mechanism enables songbirds to faithfully transmit local song dialects (Mundinger, 1980). A similar process of template matching might occur in the

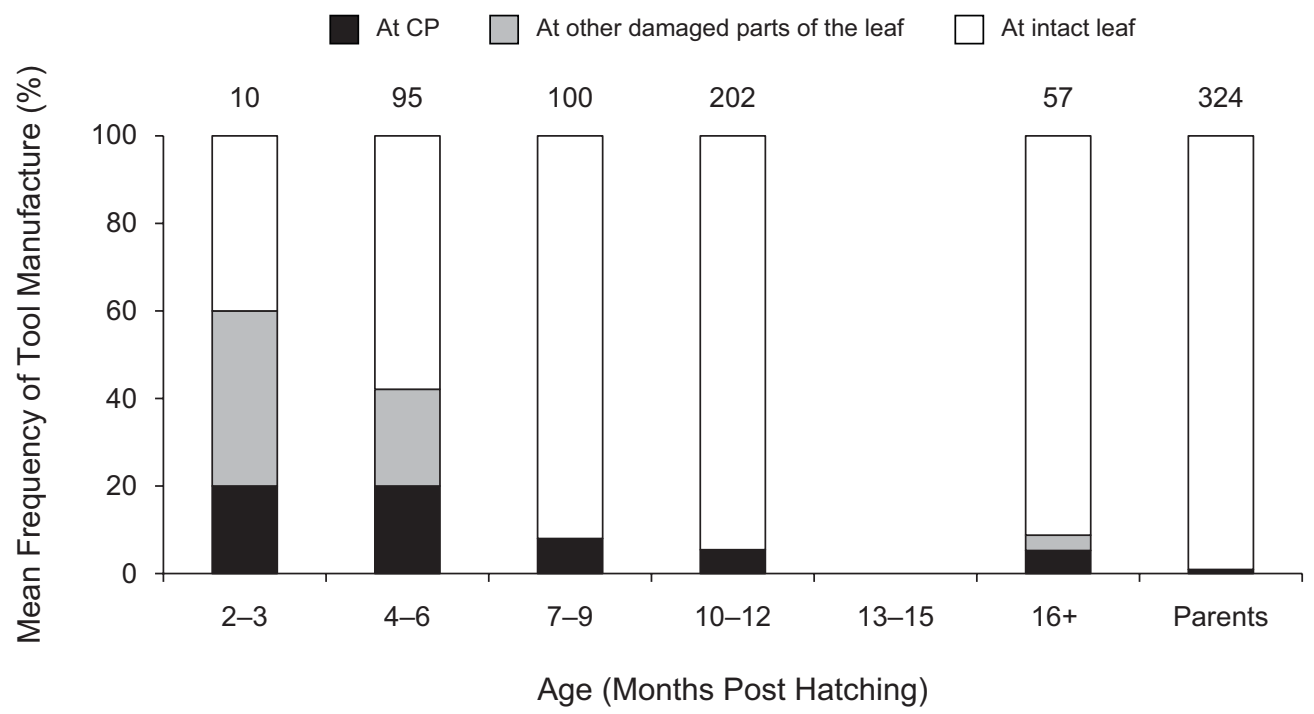

Figure 7. Average frequency of Pandanus tool manufacture starting at counterparts (CP) or other damaged parts of the leaf. Numbers on top of the bars give the total number of tool manufactures per age class. 


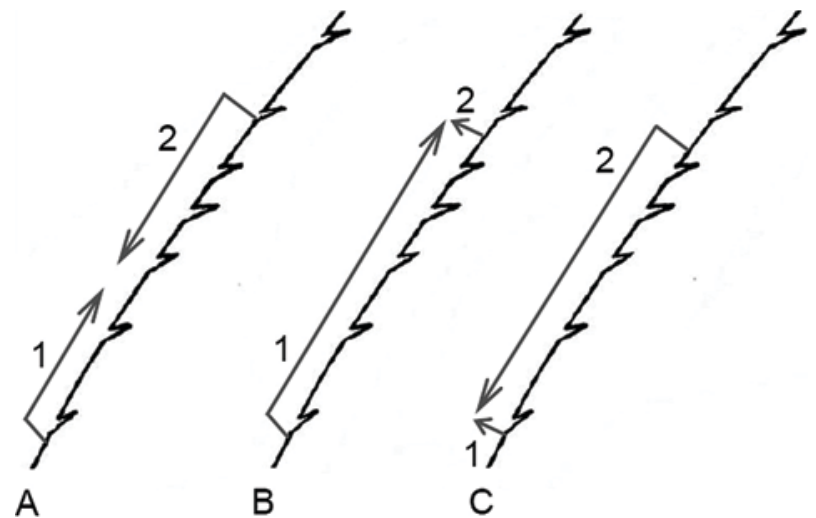

Figure 8. Variants of Pandanus tool manufacture. Variant A: Two cut-rip sequences converge about halfway along the tool. Variant B: A cut-rip (1) is followed by a cut (2). Variant C: A cut (1) is followed by a cut-rip (2).

development of NC crow tool manufacture, with juveniles gradually adjusting the shape of their own tools to the design manufactured by their parents.

\section{The Social Structure of NC Crows}

To describe NC crows' social system, we used two approaches. To assess the crows' family structure, we analyzed all observations of individuals of nine target families both at and away from tables. We then determined on how many observation days partners were seen with each other and how frequently juveniles and their parents were observed together. We also documented the breeding behavior of four breeding pairs and the extent of parental care (in particular, parental feeding) postfledging.
To assess the crows' social-network size, we recorded the number of family and nonfamily members that adult males from our target families tolerated at the tables in any 1 year.

Family structure. We found that, as in other corvid species, breeding pairs of NC crows live year round in stable, monogamous, potentially lifelong relationships. The female usually incubates and broods the eggs, whereas both partners feed the juveniles before and after fledging. On a social scale, however, NC crows are at the lower end of corvid sociality. For example, rooks can nest within colonies of hundreds of pairs and may assemble in winter roosts of tens of thousands of individuals (Clayton \& Emery, 2007). Pinyon jays live in permanent flocks of 50 to 500 individuals (Balda \& Bateman, 1971; Marzluff \& Balda, 1989). In the highly social Mexican jay (Aphelocoma ultramarine), two adult pairs typically share a territory with numerous nonbreeding helpers, all of whom participate in feeding the juveniles and defending the territory (Clayton \& Emery, 2007). In contrast, NC crows' core social unit is the immediate family, consisting of a mated pair and their offspring from up to 2 consecutive years. These findings confirm early observations on wild NC crows by Hunt (2000b) and Kenward et al. (2004).

Juveniles delay dispersal for up to 20 months (Figure 10) and may be fed by both parents throughout this time, except during the breeding season following their fledging. We found no indication of communal breeding or helpers at the nest, and we have not observed any birds other than parents feeding juveniles.

Social network size. Because feeding tables were highly desirable food sources, any bird on a table was likely to be perceived as a competitor for food. Food shar-

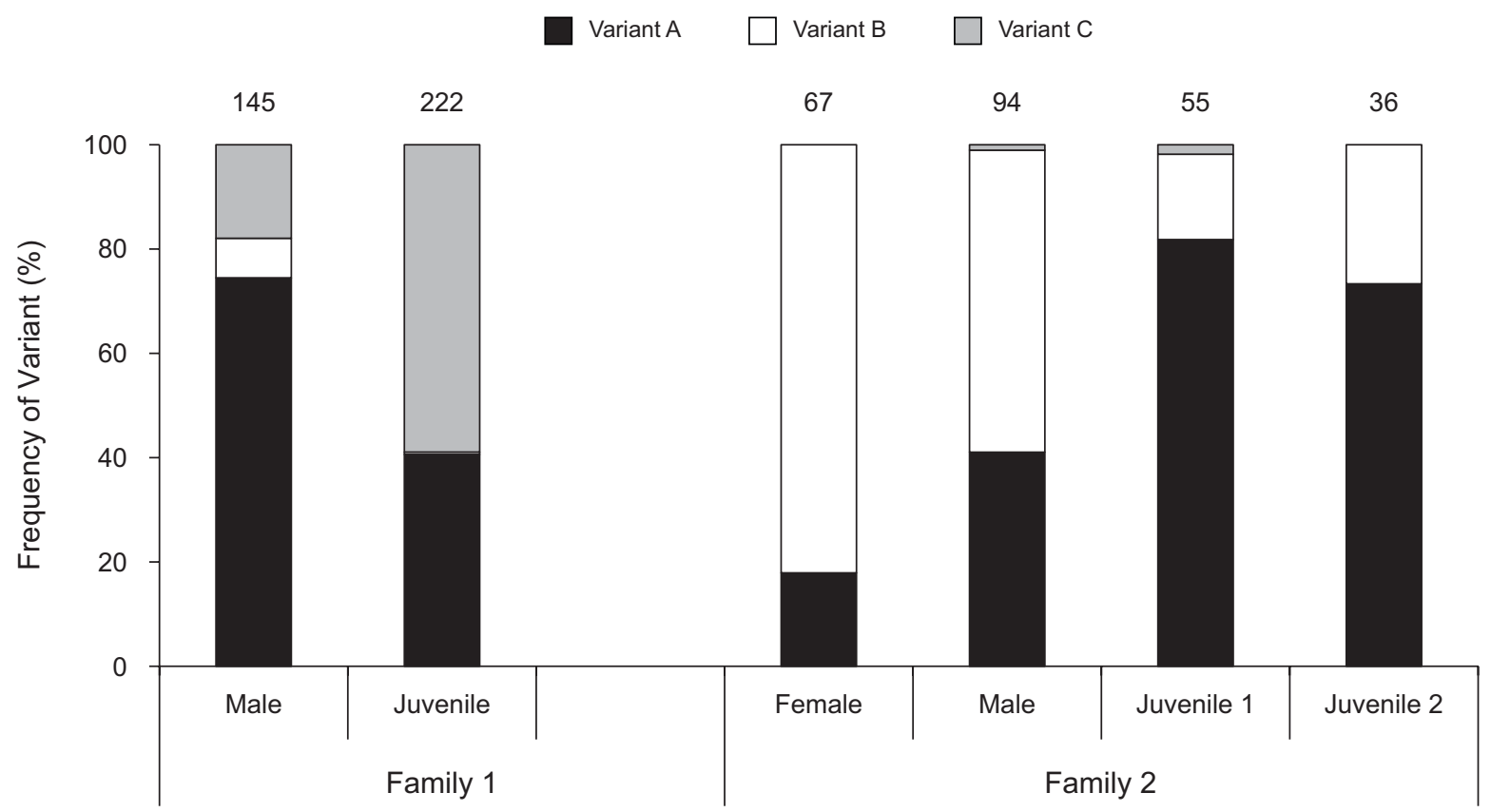

Figure 9. Variants of adult-like tool manufacture in two crow families. Note that the juveniles of Family 2 hatched in 2 consecutive years; they spent only limited time at the tables together. Sample sizes for the number of tools manufactured are above bars. 


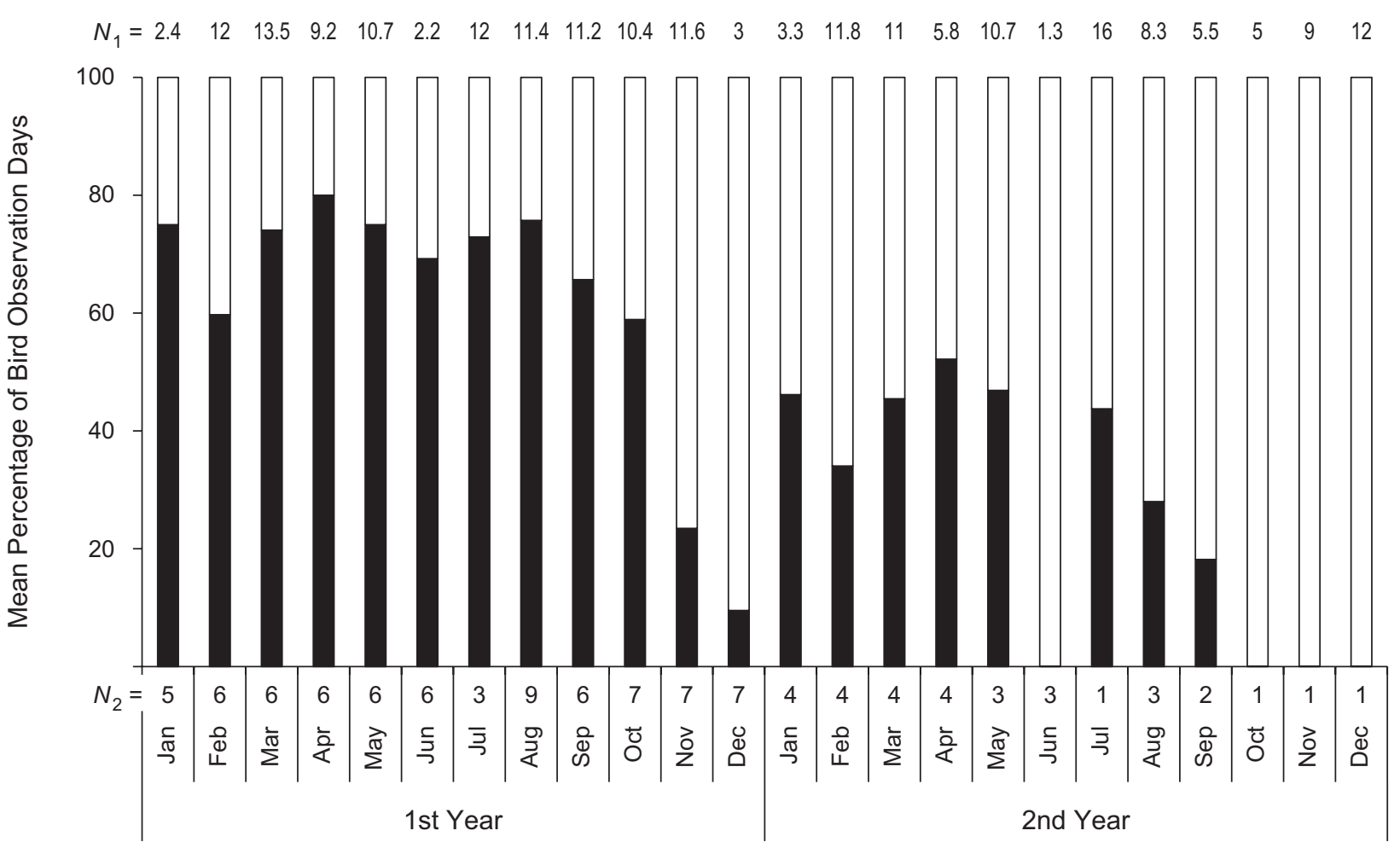

Figure 10. Observations of juveniles traveling with their parents. Juveniles travel with their parents during the first 2 years of their lives. The $y$-axis gives the mean percentage of bird observation days/month on which juveniles were seen with one or both parents. $N_{1}=$ mean bird observation days/month (maximum of 1 observation per juvenile per day); $N_{2}=$ number of juveniles observed in each month. Black bars, percentage of days observed with parents; white bars, percentage of days observed without parents.

ing has been suggested to play an important role in the development of social bonds in corvids, such as jackdaws (Corvus monedula) (von Bayern, de Kort, Clayton, \& Emery, 2007) and rooks (Emery, Seed, von Bayern, \& Clayton, 2007). Similarly, many primate species generally share food only with individuals with whom they have established social relationships (de Waal, 1989; Stevens \& Gilby, 2004). A conspecific tolerated on a table would be expected to be individually "known" to a target animal.

Target males predominantly shared tables with immediate family (i.e., partner and/or juveniles; Figure 11) and tolerated an average of 9 different nonfamily crows on tables during the course of the study. They tolerated more different nonfamily juveniles (mean of 6 different individuals per male) than different nonfamily adults (mean of 3 different individuals per male). The reason for the greater tolerance of nonfamily juveniles might be that they commonly display submissively when near a nonfamily adult and are therefore less of a potential threat. Consequently, adult males might tolerate nonfamily juveniles without having had previous interactions with them.

\section{Implications for Understanding Tool Behavior by Crows on Grande Terre}

Can the aforementioned findings on crow sociality and the development of wide tool manufacture on Maré help explain the existence and geographical distribution of different Pandanus tool designs on mainland Grande Terre?
Hunt and Gray (2003) suggested that complex, stepped Pandanus tools evolved through cumulative improvements to the simpler wide-tool design. That is, the stepped design was selected because of its superior properties as a tool (a stiff holding end combined with a narrow, flexible probing end). The absence of simpler tools in most areas where the stepped design is found and the wide distribution of the stepped design, as compared with the narrow and wide design, are consistent with this theory. An important requirement for this scenario is the faithful transmission of tool designs.

Social transmission within a population may generally be either vertical (from parent to offspring) or horizontal (between unrelated individuals) (Cavalli-Sforza \& Feldman, 1981; but see Allison, 1992; Boyd \& Richerson, 1985; Findlay, Hansell, \& Lumsden, 1989, for more detailed definitions). Individual improvements to techniques are unlikely to become established if there is a strong possibility of horizontal transmission (Sterelny, 2006). This is because horizontal transmission would provide a multitude of different variations to choose from, "diluting" improvements made by parents. Vertical transmission is therefore considered to be crucial to create a ratchet effect to maintain individual improvements that are not influenced by horizontal transmission (Sterelny, 2006).

The social organization of NC crows on Maré is likely to facilitate vertical transmission while minimizing the opportunity for horizontal transmission. First, the crows 


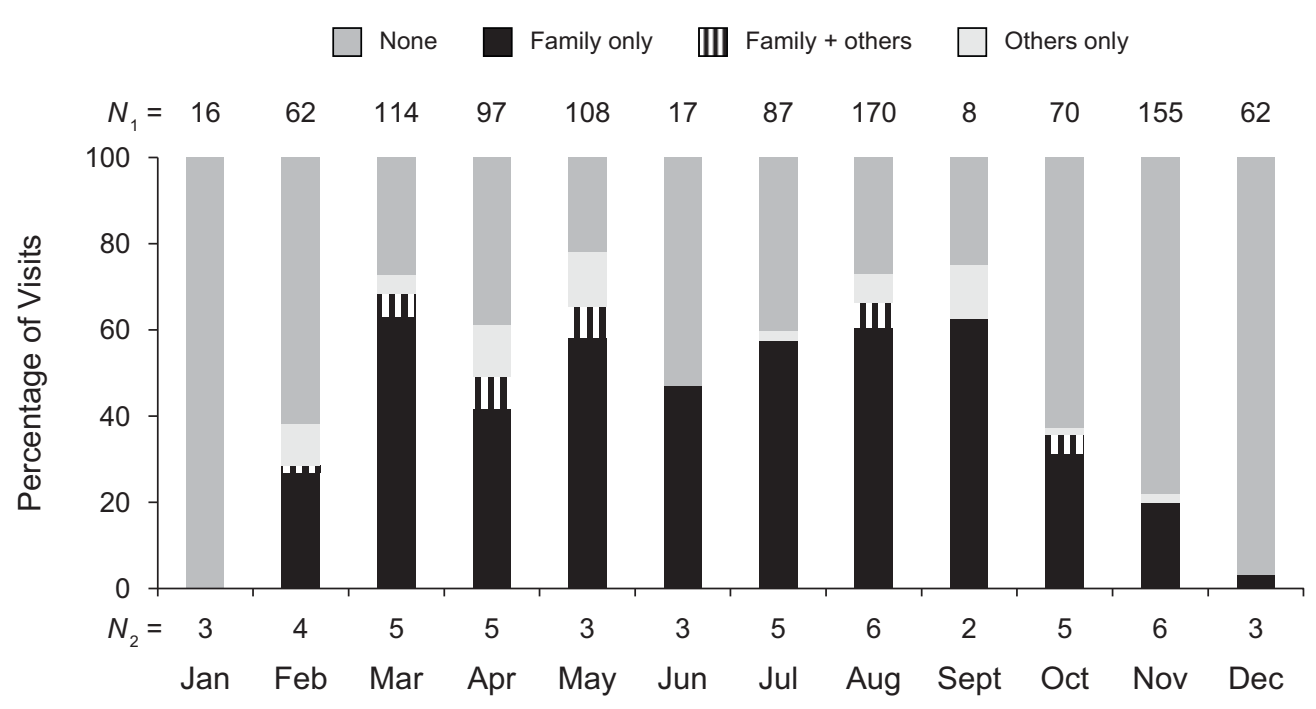

Figure 11. Tolerance of other birds by 6 target males at feeding tables. Family members are more frequently tolerated than nonfamily members. $N_{1}=$ total number of visits by all 6 target males; $N_{2}=$ number of target males observed in each month.

clearly prefer to interact with family members and only rarely share rich food sources (like feeding tables and, presumably, Pandanus trees away from tables) with nonfamily individuals. When sharing a feeding table with family members, 1st-year juveniles are much more likely to be in the company of their parents than with older siblings. Of the over 300 visits to tables by 1 st-year juveniles with at least one parent, older siblings were present on only 18 occasions. Although juveniles also shared tables with nonfamily crows, and target males appeared to be more tolerant of nonfamily juveniles than of adults, the opportunity for 1st-year crows to learn tool skills from their parents (vertical transmission) was much greater than the opportunity to learn from nonfamily birds (horizontal transmission, as defined previously). This is because juveniles that shared a table with their parents often approached them very closely when they were engaged in tool use, sometimes even touching the tool as the parent was probing. In contrast, we never observed a juvenile getting this close to an unrelated adult while using or manufacturing Pandanus tools. Instead, juveniles tended to keep their distance and often displayed submissively. Furthermore, visits in which juveniles shared a table with an unrelated adult were less frequent and tended to be much briefer than visits with family members.

The extended close association between juveniles and parents also makes it more likely that juveniles will observe their parents' tool manufacture, and it increases the chance of their using their parents' tools or starting manufacture at counterparts the parents have produced, rather than interacting with artifactual material produced by other birds. Moreover, the developmental pattern of tool manufacture indicates that the most important period for acquiring tool manufacture skills is within the first 3 to 6 months of life. Thereafter, tool manufacturing techniques are largely adult like (Figure 4). Although juveniles spend less time with their parents from 6 to 9 months of age than they did at earlier ages, they are unlikely to adopt different strategies used by unrelated crows since they have already settled on a manufacture variant.

Could the social behavior of the crows on Mare enable high-fidelity transmission of tool information? Theoretically, yes. Close proximity between individuals increases the likelihood that one can observe details of the other's behavior (Coussi-Korbel \& Fragaszy, 1995). Van Schaik, Deaner, and Merrill (1999) claimed that strong mutual tolerance between individuals was a key factor in the evolution of technology among hominids and was facilitated by a lifestyle involving food sharing and tool-based processing of food.

Our methodology does not allow us to distinguish between possible observational learning mechanisms such as imitation or emulation. However, young crows clearly have ample opportunity to watch tool manufacture and tool use closely, and to use artifactual material produced by their parents. Our results also strongly indicate that trial and error plays a central role in the development of juvenile tool manufacture and use. Trial and error has also been suggested to be important in children's obtaining significant knowledge about the physical properties of their tools (Lockman, 2000). Nevertheless, as Kenward et al. (2005) pointed out, an important role for trial-anderror learning does not exclude the possibility that either children or NC crows learn important details about manufacture techniques and tool shape culturally. Such social learning might either be a result of direct observation or possibly be acquired less directly via "external memory" located in artifactual material, such as tools and counterparts produced by adults.

\section{Conclusion}

Different kinds of social learning may play a significant role in NC crows' development of tool manufacture and use. Both the social organization of NC crows and the 
way that tool skills develop have the capacity to facilitate faithful transmission of tool designs by encouraging vertical transmission and minimizing horizontal transmission. However, several questions remain about the development and geographical distribution of different Pandanus tool designs on New Caledonia's mainland, Grande Terre. For example, we know nothing about the ontogeny of stepped Pandanus tool manufacture and use.

Our observations on Maré suggest that social learning may be involved in the development of wide tool manufacture. However, wide tools are relatively simple to manufacture. The strong parallel fibers of Pandanus species leaves facilitate the production of uniformly wide strips of material. As Kenward et al. (2005) showed, naive crows can produce rough strips of Pandanus leaf that are suitable for meat extraction, without social input.

Although it is possible that naive juveniles can develop adult-like wide tool manufacture by individual trial-anderror learning alone, it is difficult to imagine that the more complicated stepped tools are produced in this way. We also do not know whether an individual crow can produce more than one Pandanus tool design or whether stepped tools are really more efficient in extracting prey than the simpler wide and narrow designs. Controlled experiments are also needed to further investigate the possibility of information transmission via template matching.

Finally, the social organization of $\mathrm{NC}$ crows on Maré that is based around small family groups and the delayed dispersal of juveniles is likely to be comparable to that of crows on Grande Terre. However, we know little about the factors surrounding juvenile dispersal from the family unit. Investigating this aspect of the $\mathrm{NC}$ crows' social system is important because dispersal dynamics have implications for the spread and geographical distribution of tool designs (Lind \& Lindenfors, 2010).

\section{AUTHOR NOTE}

We thank William Wadrobert for kindly allowing us to work on his family's land in Wabao District, Maré, and the Province des Iles Loyauté for permission to work on Maré. Mick Sibley prepared DVD versions of the video footage. Noel Andrews, Lindsey Davidson, Roland Rehm, Robert Ross, Mick Sibley, and Alex Taylor assisted with data collection. We thank Katie Palmer for help with the coding of video footage, Puja Singh for help with the coding and processing of the sociality data, Vivian Ward for drawing Figure 3, and Roland Rehm for the production of Figure 5. Jeff Galef provided many helpful comments that improved the manuscript. This research was funded by a grant from the New Zealand Marsden Fund (awarded to R.D.G. and G.R.H.). The research reported in this article was approved by the University of Auckland Animal Ethics Committee (approvals R231 and R375) and complies with the laws of New Caledonia. Address correspondence to J. C. Holzhaider, Department of Psychology, University of Auckland, Private Bag 92019, Auckland 1142, New Zealand (e-mail: jenny.holzhaider@gmail.com).

\section{REFERENCES}

Allison, P. D. (1992). Cultural relatedness under oblique and horizontal transmission rules. Ethology \& Sociobiology, 13, 153-169.

Avital, E., \& JablonKa, E. (2000). Animal traditions: Behavioural inheritance in evolution. Cambridge: Cambridge University Press.

Baker, M. C., \& Cunningham, M. A. (1985). The biology of bird-song dialects. Behavioral \& Brain Sciences, 8, 85-133.

Balda, R. P., \& Bateman, G. C. (1971). Flocking and annual cycle of the piñon jay, Gymnorhinus cyanocephalus. Condor, 73, 287-302.

BIRD, C. D., \& EMERY, N. J. (2009). Insightful problem solving and cre- ative tool modification by captive nontool-using rooks. Proceedings of the National Academy of Sciences, 106, 10370-10375.

Bird, C. D., \& EMERY, N. J. (2010). Rooks perceive support relations similar to six-month-old babies. Proceedings of the Royal Society B, 277, 147-151.

Biro, D., Sousa, C., \& Matsuzawa, T. (2006). Ontogeny and cultural propagation of tool use by wild chimpanzees at Bossou, Guinea: Case studies in nut cracking and leaf folding. In T. Matsuzawa, M. Tomonaga, \& M. Tanaka (Eds.), Cognitive development in chimpanzees (pp. 476-508). Tokyo: Springer.

Bluff, L. A., Troscianko, J., Weir, A. A. S., Kacelnik, A., \& Rutz, C. (2010). Tool use by wild New Caledonian crows Corvus moneduloides at natural foraging sites. Proceedings of the Royal Society B, 277, 1377-1385.

Boesch, C., Head, J., \& Robbins, M. M. (2009). Complex tool sets for honey extraction among chimpanzees in Loango National Park, Gabon. Journal of Human Evolution, 56, 560-569.

Boserup, E. (1981). Population and technological change: A study of long-term trends. Chicago: University of Chicago Press.

Box, H. O. (1984). Primate behaviour and social ecology. London: Chapman \& Hall.

Boyd, R., \& Richerson, P. J. (1985). Culture and the evolutionary process. Chicago: University of Chicago Press.

Boyd, R., \& Richerson, P. J. (1996). Why culture is common, but cultural evolution is rare. Proceedings of the British Academy, 88, 77-93.

BugnYar, T. (2008). Animal cognition: Rooks team up to solve a problem. Current Biology, 18, R530-R532.

Caldwell, C. A., \& Whiten, A. (2003). Scrounging facilitates social learning in common marmosets, Callithrix jacchus. Animal Behaviour, 65, 1085-1092.

Call, J., Carpenter, M., \& Tomasello, M. (2005). Copying results and copying actions in the process of social learning: Chimpanzees (Pan troglodytes) and human children (Homo sapiens). Animal Cognition, 8, 151-163.

Call, J., \& Tomasello, M. (1994). The social learning of tool use by orangutans (Pongo pygmaeus). Human Evolution, 9, 297-313.

Catchpole, C. K., \& Slater, P. J. B. (1995). Bird song: Biological themes and variations. Cambridge: Cambridge University Press.

Cavalli-Sforza, L. L., \& Feldman, M. W. (1981). Cultural transmission and evolution: A quantitative approach. Princeton, NJ: Princeton University Press.

Chappell, J., \& KaCelniK, A. (2002). Tool selectivity in a non-primate, the New Caledonian crow (Corvus moneduloides). Animal Cognition, 5, 71-78.

Chappell, J., \& Kacelnik, A. (2004). Selection of tool diameter by New Caledonian crows (Corvus moneduloides). Animal Cognition, 7, 121-127.

Claidière, N., \& Sperber, D. (2010). Imitation explains the propagation, not the stability of animal culture. Proceedings of the Royal Society B, 277, 651-659.

Clayton, N. S., \& Emery, N. J. (2007). The social life of corvids. Current Biology, 17, R652-R656.

Cnotka, J., GÜntürkün, O., RehKämper, G., Gray, R. D., \& Hunt, G. R. (2008). Extraordinary large brains in tool-using New Caledonian crows (Corvus moneduloides). Neuroscience Letters, 433, 241-245.

Connolly, K., \& Dalgleish, M. (1989). The emergence of a tool-using skill in infancy. Developmental Psychology, 25, 894-912.

Coussi-Korbel, S., \& Fragaszy, D. M. (1995). On the relation between social dynamics and social learning. Animal Behaviour, 50, 1441-1453.

de Resende, B. D., Ottoni, E. B., \& Fragaszy, D. M. (2008). Ontogeny of manipulative behavior and nut-cracking in young tufted capuchin monkeys (Cebus apella): A perception-action perspective. Developmental Science, 11, 828-840.

DE WAAL, F. B. M. (1989). Food sharing and reciprocal obligations among chimpanzees. Journal of Human Evolution, 18, 433-459.

Donald, M. (1991). Origins of the modern mind: Three stages in the evolution of culture and cognition. Cambridge, MA: Harvard University Press.

Doupe, A. J., \& Konishi, M. (1991). Song-selective auditory circuits in the vocal control system of the zebra finch. Proceedings of the National Academy of Sciences, 88, 11339-11343.

EMERY, N. J. (2004). Are corvids "feathered apes"?: Cognitive evolution 
in crows, jays, rooks and jackdaws. In S. Watanabe (Ed.), Comparative analysis of mind (pp. 181-213). Tokyo: Keio University Press.

Emery, N. J. (2006). Cognitive ornithology: The evolution of avian intelligence. Philosophical Transactions of the Royal Society B, 361, 23-43.

Emery, N. J., \& Clayton, N. S. (2004). The mentality of crows: Convergent evolution of intelligence in corvids and apes. Science, 306, 1903-1907.

Emery, N. J., \& Clayton, N. S. (2009). Tool use and physical cognition in birds and mammals. Current Opinion in Neurobiology, 19, 27-33.

Emery, N. J., Seed, A. M., von Bayern, A. M. P., \& Clayton, N. S. (2007). Cognitive adaptations of social bonding in birds. Philosophical Transactions of the Royal Society B, 362, 489-505.

Findlay, C. S., Hansell, R. I. C., \& Lumsden, C. J. (1989). Behavioral evolution and biocultural games: Oblique and horizontal cultural transmission. Journal of Theoretical Biology, 137, 245-269.

Fragaszy, D. M., \& Visalberghi, E. (1996). Social learning in monkeys: Primate "primacy" reconsidered. In C. M. Heyes \& B. G. Galef, Jr. (Eds.), Social learning in animals: The roots of culture (pp. 65-84). San Diego: Academic Press.

GALEF, B. G., JR. (1988). Imitation in animals: History, definition, and interpretation of data from the psychological laboratory. In T. R. Zentall \& B. G. Galef, Jr. (Eds.), Social learning: Psychological and biological perspectives (pp. 3-28). Hillsdale, NJ: Erlbaum.

GiraldeaU, L.-A., \& LefebVRe, L. (1987). Scrounging prevents cultural transmission of food-finding behaviour in pigeons. Animal Behaviour, 35, 387-394.

Hernandez-Aguilar, R. A., Moore, J., \& Pickering, T. R. (2007). Savanna chimpanzees use tools to harvest the underground storage organs of plants. Proceedings of the National Academy of Sciences, 104, 19210-19213.

Heyes, C. M. (1993). Imitation, culture and cognition. Animal Behaviour, 46, 999-1010.

HeYES, C. M. (1994). Social learning in animals: Categories and mechanisms. Biological Reviews, 69, 207-231.

Hirata, S., \& Celli, M. L. (2003). Role of mothers in the acquisition of tool-use behaviours by captive infant chimpanzees. Animal Cognition, 6, 235-244.

Hirata, S., \& Morimura, N. (2000). Naive chimpanzees' (Pan troglodytes) observation of experienced conspecifics in a tool-using task. Journal of Comparative Psychology, 114, 291-296.

Holzhaider, J. C., Hunt, G. R., \& Gray, R. D. (2010). The development of Pandanus tool manufacture in wild New Caledonian crows. Behaviour, 147, 553-586.

Holzhaider, J. C., Sibley, M. D., Taylor, A. H., Singh, P. J., Gray, R. D., \& Hunt, G. R. (in press). The social structure of New Caledonian crows. Animal Behaviour.

Horner, V., \& Whiten, A. (2005). Causal knowledge and imitation/ emulation switching in chimpanzees (Pan troglodytes) and children (Homo sapiens). Animal Cognition, 8, 164-181.

Humle, T. (2006). Ant dipping in chimpanzees: An example of how microecological variables, tool use, and culture reflect the cognitive abilities of chimpanzees. In T. Matsuzawa, M. Tomonaga, \& M. Tanaka (Eds.), Cognitive development in chimpanzees (pp. 452475). Tokyo: Springer.

Hunt, G. R. (1996). Manufacture and use of hook-tools by New Caledonian crows. Nature, 379, 249-251.

Hunt, G. R. (2000a). Human-like, population-level specialization in the manufacture of Pandanus tools by New Caledonian crows Corvus moneduloides. Proceedings of the Royal Society B, 267, 403-413.

Hunt, G. R. (2000b). Tool use by the New Caledonian crow Corvus moneduloides to obtain Cerambycidae from dead wood. Emu, 100, 109-114.

Hunt, G. R., \& GRAY, R. D. (2002). Species-wide manufacture of sticktype tools by New Caledonian Crows. Emu, 102, 349-353.

Hunt, G. R., \& Gray, R. D. (2003). Diversification and cumulative evolution in New Caledonian crow tool manufacture. Proceedings of the Royal Society B, 270, 867-874.

Hunt, G. R., \& Gray, R. D. (2004a). The crafting of hook tools by wild New Caledonian crows. Proceedings of the Royal Society B, 271, 88-90.

Hunt, G. R., \& Gray, R. D. (2004b). Direct observations of Pandanus- tool manufacture and use by a New Caledonian crow (Corvus moneduloides). Animal Cognition, 7, 114-120.

Hunt, G. R., \& Gray, R. D. (2007). Parallel tool industries in New Caledonian crows. Biology Letters, 3, 173-175.

Hunt, G. R., Lambert, C., \& Gray, R. D. (2007). Cognitive requirements for tool use by New Caledonian crows. New Zealand Journal of Zoology, 34, 1-7.

Inoue-NaKamura, N., \& Matsuzawa, T. (1997). Development of stone tool use by wild chimpanzees (Pan troglodytes). Journal of Comparative Psychology, 111, 159-173.

Jaeggi, A. V., Dunkel, L. P., Van Noordwijk, M. A., Wich, S. A., Sura, A. A. L., \& VAn Schaik, C. P. (2010). Social learning of diet and foraging skills by wild immature Bornean orangutans: Implications for culture. American Journal of Primatology, 72, 62-71.

JERISON, H. J. (1973). Evolution of the brain and intelligence. New York: Academic Press.

KAWAI, M. (1965). Newly-acquired pre-cultural behavior of the natural troop of Japanese monkeys on Koshima islet. Primates, 6, 1-30.

Kendal, R. L., Custance, D. M., Kendal, J. R., Vale, G., StoinSki, T. S., Rakotomalala, N. L., \& Rasamimanana, H. (2010). Evidence for social learning in wild lemurs (Lemur catta). Learning \& Behavior, 38, 220-234.

Kendal, R. L., Kendal, J. R., Hoppitt, W., \& Laland, K. N. (2009). Identifying social learning in animal populations: A new "option-bias" method. PLoS ONE, 4, e6541. doi:10.1371/journal.pone.0006541

Kenward, B., Rutz, C., Weir, A. A. S., Chappell, J., \& Kacelnik, A. (2004). Morphology and sexual dimorphism of the New Caledonian Crow Corvus moneduloides, with notes on its behaviour and ecology. Ibis, 146, 652-660.

Kenward, B., Rutz, C., Weir, A. A. S., \& Kacelnik, A. (2006). Development of tool use in New Caledonian crows: Inherited action patterns and social influences. Animal Behaviour, 72, 1329-1343.

Kenward, B., Weir, A. A. S., Rutz, C., \& Kacelnik, A. (2005). Behavioural ecology: Tool manufacture by naive juvenile crows. Nature, 433, 121.

Konishi, M. (1985). Birdsong: From behavior to neuron. Annual Review of Neuroscience, 8, 125-170.

Laland, K. N., \& HoppitT, W. (2003). Do animals have culture? Evolutionary Anthropology: Issues, News, \& Reviews, 12, 150-159.

Laland, K. N., Odling-Smee, J., \& Feldman, M. W. (2000). Niche construction, biological evolution, and cultural change. Behavioral \& Brain Sciences, 23, 131-146.

Lind, J., \& Lindenfors, P. (2010). The number of cultural traits is correlated with female group size but not with male group size in chimpanzee communities. PLOS ONE, 5, e9241. doi:10.1371/journal .pone.0009241

LOCKMAN, J. J. (2000). A perception-action perspective on tool use development. Child Development, 71, 137-144.

Marler, P., \& TAmura, M. (1964). Culturally transmitted patterns of vocal behavior in sparrows. Science, 146, 1483-1486.

Marzluff, J. M., \& Balda, R. P. (1989). Causes and consequences of female-biased dispersal in a flock-living bird, the Pinyon Jay. Ecology, 70, 316-328.

Matsuzawa, T. (1994). Field experiments on use of stone tool by chimpanzees in the wild. In R. W. Wrangham, W. C. McGrew, F. B. M. de Waal, \& P. Heltne (Eds.), Chimpanzee cultures (pp. 351-370). Cambridge, MA: Harvard University Press.

Matsuzawa, T., Biro, D., Humle, T., Inoue-Nakamura, N., ToNOOKA, R., \& YAMAKoshi, G. (2001). Emergence of culture in wild chimpanzees: Education by master-apprenticeship. In T. Matsuzawa (Ed.), Primate origins of human cognition and behavior (pp. 557574). Tokyo: Springer.

McGrew, W. C. (1992). Chimpanzee material culture: Implications for human evolution. Cambridge: Cambridge University Press.

Mehlhorn, J., Hunt, G. R., Gray, R. D., Rehkämper, G., \& GÜnTÜRKüN, O. (2010). Tool-making New Caledonian crows have large associative brain areas. Brain, Behavior \& Evolution, 75, 63-70.

Midford, P. E., Hailman, J. P., \& Woolfenden, G. E. (2000). Social learning of a novel foraging patch in families of free-living Florida scrub-jays. Animal Behaviour, 59, 1199-1207.

Mundinger, P. C. (1980). Animal cultures and a general theory of cultural evolution. Ethology \& Sociobiology, 1, 183-223. 
Myowa-Yamakoshi, M., \& MatsuZawa, T. (1999). Factors influencing imitation of manipulatory actions in chimpanzees (Pan troglodytes). Journal of Comparative Psychology, 113, 128-136.

Nagell, K., Olguin, R. S., \& Tomasello, M. (1993). Processes of social learning in the tool use of chimpanzees (Pan troglodytes) and human children (Homo sapiens). Journal of Comparative Psychology, 107, 174-186.

Nishida, T., \& HiRAiwa, M. (1982). Natural history of a tool-using behavior by wild chimpanzees in feeding upon wood-boring ants. Journal of Human Evolution, 11, 73-99.

Noad, M. J., Cato, D. H., Bryden, M. M., Jenner, M.-N., \& Jenner, K. C. S. (2000). Cultural revolution in whale songs. Nature, $\mathbf{4 0 8 \text { , }}$ 537.

Nоттевонм, F. (1984). Birdsong as a model in which to study brain processes related to learning. Condor, 86, 227-236.

Odling-Smee, F. J., Laland, K. N., \& Feldman, M. W. (2003). Niche construction: The neglected process in evolution. Princeton, NJ: Princeton University Press.

OtTONI, E. B., \& IZAR, P. (2008). Capuchin monkey tool use: Overview and implications. Evolutionary Anthropology: Issues, News, \& Reviews, 17, 171-178.

Perry, S., Panger, M., Rose, L. M., Baker, M., Gros-Louis, J., JACK, K., ET AL. (2003). Traditions in wild white-faced capuchin monkeys. In D. M. Fragaszy \& S. Perry (Eds.), The biology of traditions: Models and evidence (pp. 391-425). Cambridge: Cambridge University Press.

READER, S. M., \& BIRo, D. (2010). Experimental identification of social learning in wild animals. Learning \& Behavior, 38, 265-283.

RehKäMPer, G., Frahm, H. D., \& Zilles, K. (1991). Quantitative development of brain and brain structures in birds (galliformes and passeriformes) compared to that in mammals (insectivores and primates). Brain, Behavior \& Evolution, 37, 125-143.

Reiner, A., Perkel, D. J., Bruce, L. L., Bulter, A. B., Csillag, A., KuenZEL, W., ET AL. (2004). Revised nomenclature for avian telencephalon and some related brainstem nuclei. Journal of Comparative Neurology, 473, 377-414.

ReISMAN, K. (2007). Is culture inherited through social learning? Biological Theory, 2, 300-306.

Rendell, L., \& Whitehead, H. (2001). Culture in whales and dolphins. Behavioral \& Brain Sciences, 24, 309-382.

Rutz, C., Bluff, L. A., Weir, A. A. S., \& Kacelnik, A. (2007). Video cameras on wild birds. Science, 318, 765 .

Sanz, C., Call, J., \& Morgan, D. (2009). Design complexity in termite-fishing tools of chimpanzees (Pan troglodytes). Biology Letters, 5, 293-296.

Sanz, C., Morgan, D., \& Gulick, S. (2004). New insights into chimpanzees, tools, and termites from the Congo basin. American Naturalist, 164, 567-581.

SeEd, A., Emery, N., \& Clayton, N. (2009). Intelligence in corvids and apes: A case of convergent evolution? Ethology, 115, 401-420.

Sterelny, K. (2006). The evolution and evolvability of culture. Mind \& Language, 21, 137-165.

Stevens, J. R., \& Gilby, I. C. (2004). A conceptual framework for nonkin food sharing: Timing and currency of benefits. Animal Behaviour, 67, 603-614.

Taylor, A. H., Hunt, G. R., Holzhaider, J. C., \& Gray, R. D. (2007). Spontaneous metatool use by New Caledonian crows. Current Biology, 17, 1504-1507.

Taylor, A. H., Hunt, G. R., Medina, F. S., \& Gray, R. D. (2009). Do New Caledonian crows solve physical problems through causal reasoning? Proceedings of the Roval Society B, 276, 247-254.

Taylor, A. H., Medina, F. S., Holzhaider, J. C., Hearne, L. J., Hunt, G. R., \& Gray, R. D. (2010). An investigation into the cognition behind spontaneous string pulling in New Caledonian crows. PLoS ONE, 5, e9345.

TAYlor, A. H., Roberts, R., Hunt, G. R., \& Gray, R. D. (2009). Causal reasoning in New Caledonian crows: Ruling out spatial analogies and sampling error. Communicative \& Integrative Biology, 2, 311-312.
Tebbich, S., Seed, A. M., Emery, N. J., \& Clayton, N. S. (2007). Non-tool-using rooks, Corvus frugilegus, solve the trap-tube problem. Animal Cognition, 10, 225-231.

Tebbich, S., Taborsky, M., Fessl, B., \& Blomovist, D. (2001). Do woodpecker finches acquire tool-use by social learning? Proceedings of the Royal Society B, 268, 2189-2193.

TERKEL, J. (1996). Cultural transmission of feeding behavior in the black rat (Rattus rattus). In C. M. Heyes \& B. G. Galef, Jr. (Eds.), Social learning in animals: The roots of culture (pp. 17-47). San Diego: Academic Press.

Thouless, C. R., Fanshawe, J. H., \& Bertram, B. C. R. (1989). Egyptian vultures Neophron percnopterus and ostrich Struthio camelus eggs: The origins of stone throwing behavior. Ibis, 131, 9-15.

Tomasello, M. (1996). Do apes ape? In C. M. Heyes \& B. G. Galef, Jr. (Eds.), Social learning in animals: The roots of culture (pp. 319-346). London: Academic Press.

Tomasello, M. (1999). The human adaptation for culture. Annual Review of Anthropology, 28, 509-529.

Tomasello, M. (2005). Uniquely human cognition is a product of human culture. In S. C. Levinson \& P. Jaisson (Eds.), Evolution and culture: A Fyssen Foundation symposium (pp. 203-218). Cambridge, MA: MIT Press.

Tomasello, M., Davis-Dasilva, M., CamaK, L., \& Bard, K. (1987). Observational learning of tool-use by young chimpanzees. Human Evolution, 2, 175-183.

Tomasello, M., Kruger, A. C., \& Ratner, H. H. (1993). Cultural learning. Behavioral \& Brain Sciences, 16, 495-552.

Tomasello, M., Savage-Rumbaugh, S., \& Kruger, A. C. (1993). Imitative learning of actions on objects by children, chimpanzees, and enculturated chimpanzees. Child Development, 64, 1688-1705.

van Schaik, C. P., Ancrenaz, M., Borgen, G., Galdikas, B., Knott, C. D., Singleton, I., ET AL. (2003). Orangutan cultures and the evolution of material culture. Science, 299, 102-105.

van Schaik, C. P., Deaner, R. O., \& Merrill, M. Y. (1999). The conditions for tool use in primates: Implications for the evolution of material culture. Journal of Human Evolution, 36, 719-741.

von Bayern, A. M. P., de Kort, S. R., Clayton, N. S., \& Emery, N. J. (2007). The role of food- and object-sharing in the development of social bonds in juvenile jackdaws (Corvus monedula). Behaviour, 144, 711-733

WANT, S. C., \& HARRIS, P. L. (2001). Learning from other people's mistakes: Causal understanding in learning to use a tool. Child Development, 72, 431-443.

Want, S. C., \& Harris, P. L. (2002). How do children ape? Applying concepts from the study of non-human primates to the developmental study of "imitation" in children. Developmental Science, 5, 1-14.

Weir, A. A. S., Chappell, J., \& KacelniK, A. (2002). Shaping of hooks in New Caledonian crows. Science, 297, 981.

Weir, A. A. S., \& KaCELniK, A. (2006). A New Caledonian crow (Corvus moneduloides) creatively re-designs tools by bending or unbending aluminium strips. Animal Cognition, 9, 317-334.

Whiten, A. (2005). The second inheritance system of chimpanzees and humans. Nature, 437, 52-55.

Whiten, A., Goodall, J., McGrew, W. C., Nishida, T., Reynolds, V., SugiYama, Y., ET AL. (1999). Cultures in chimpanzees. Nature, 399, 682-685.

Whiten, A., Horner, V., Litchfield, C. A., \& Marshall-Pescini, S. (2004). How do apes ape? Learning \& Behavior, 32, 36-52.

Whiten, A., McGuigan, N., Marshall-Pescini, S., \& Hopper, L. M. (2009). Emulation, imitation, over-imitation and the scope of culture for child and chimpanzee. Philosophical Transactions of the Royal Society $B, \mathbf{3 6 4}, 2417-2428$.

Wimpenny, J. H., Weir, A. A. S., Clayton, L., Rutz, C., \& KacelNIK, A. (2009). Cognitive processes associated with sequential tool use in New Caledonian crows. PLoS ONE, 4, e6471.

(Manuscript received March 8, 2010; revision accepted for publication April 30, 2010.) 